\title{
The Effect of Deep Breath Relaxation and Roasted Garlic Consumption on the Blood Pressure decrease in the Pressure of Elderly Hypertension
}

\author{
Susmadi Susmadi ${ }^{1}$, Anna Sunita ${ }^{1}$ (D) Gurid Pramintarto Eko Mulyo ${ }^{2 *}$ (iD \\ ${ }^{1}$ Departement of Nursing, Poltekkes Kemenkes Bandung, Bandung, Indonesia; ${ }^{2}$ Departement of Nutrition, Poltekkes Kemenkes \\ Bandung, Bandung, Indonesia
}

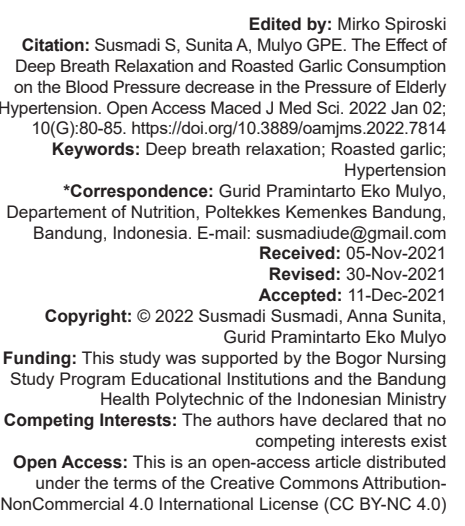

\begin{abstract}
BACKGROUND: Patients with hypertension are estimated to reach 1 billion globally, where 972 million (26\%) of the adults in the world suffer from hypertension. Predicted by 2025 , about $29 \%$ of adults worldwide suffer from hypertension, and two-thirds of them are in developing countries. Increased blood pressure (BP) that takes place in a long time can cause damage to the kidneys, heart, and brain when not detected early and received adequate treatment. The intervention of hypertension is still constrained in chemical drug pharmacological therapy. For nonpharmacological or complementary treatment such as deep breath relaxation and roasted garlic, consumption is already known in the community but not maximized utilized.
\end{abstract}

AIM: Hence, a combination of this intervention needs to be developed to assess the effect of synergies.

METHODS: The study was conducted in the west Bogor district with samples of 34 Pre-elderly and elderly respondents. Design of pre-experiment One Group Pre-Post Test Design by working combination intervention. Analysis of T-dependent tests and simple linear regression correlation.

RESULTS: There is an influence of combination intervention on the second measurement of the day of intervention of the Systolic BP ( $p$-value 0.006 ), a mean of $6.56 \mathrm{mmHg}$ decrease, against diastole BP ( $p$-value Vauile) is disclosed difference of $3.82 \mathrm{mmHg}$. In the post-intervention measurement of the Systolic BP (p-value 0.000 ) is a mean $8.86 \mathrm{mmHg}$ of diastole BP not the influence ( $p$-value 0.103 ) with a decrease of $2.60 \mathrm{mmHg}$, there is an age correlation to the average of the decision of BP of the system of the Systole ( $p$-value 0.006 ) shows the relationship and patterned positive.

CONCLUSION: They recommended research results to alternative, complementary therapy effectively lowering BP in the community.

\section{Introduction}

People with hypertension are estimated to reach 1 billion globally, and two-thirds of them are in developing countries; it is predicted that by 2025 around $29 \%$ of adults worldwide will suffer from hypertension. Based on the World Health Organization report of $50 \%$ known hypertensive patients, $25 \%$ received treatment, but only $12.5 \%$ were well treated. Meanwhile, 70 million people with hypertension in Indonesia (28\%), but only $24 \%$ are controlled hypertension [1]. West Java is one of five provinces where hypertension is relatively high, namely $29.4 \%$ [2].

There are two types of hypertension control and management, namely pharmacological and nonpharmacological. Pharmacological therapy uses anti-hypertensive drugs to lower blood pressure (BP) which is used continuously for life. Patients who are bored and do not regularly take anti-hypertensive drugs cause persistent hypertension and target organ complications. While non-pharmacological, with lifestyle modifications, especially in primary hypertension, namely; quit smoking, lose weight, avoid alcohol, modify diet, control stress, exercise, and rest [3].

Non-pharmacological hypertension treatment in the community or complementary is slow deep breathing relaxation and herbal therapy ineffective garlic consumption. Research by Tawang Tawang (2013) and Hartanti et al. (2016) found a significant relationship $(p<0.05)$ between deep breathing relaxation and a decrease in systolic and diastolic BP [4], [5]. Based on research conducted by Kartikasari in 2013, there were differences in BP before and after consumption of garlic with $p=0.001$. The decrease in diastolic before after consuming garlic was $7.00 \mathrm{mmHg}$, with a standard deviation before $=6.057(p<0.001)$, after $=6.384$, $(p=0.01[6]$.

Research on deep breathing relaxation and consumption of garlic is quite significant in reducing $\mathrm{BP}$ so that it can be used as an alternative non-pharmacological therapy. It is known that the compound allicin in garlic is efficacious in destroying the formation of blood clots in the arteries, reducing 
diabetes symptoms, and reducing BP. The same thing was found in other studies, that garlic steeping therapy was very effective in lowering both systolic and diastolic $\mathrm{BP}$, where the decrease in BP before and after being given garlic steeping therapy with a p-value of systolic and diastolic $=0.000$ [7].

Researchers are interested in combining two treatments or interventions simultaneously. Research that combines deep breathing relaxation with roasted garlic consumption is expected to lower BP faster because the effects of the two therapies can be synergistic and there are only a few studies using roasted garlic consumption.

This study aimed to obtain information about roasted garlicconsumption and deep breathing relaxation on reducing $\mathrm{BP}$ in the elderly with hypertension. This research is expected to be helpful to get an overview of Deep Breathing Relaxation and Consumption of Roasted Garlic in its effect on reducing BP in the elderly with hypertension. In addition, this research is expected to be a reference for further researchers and information about the benefits and alternative nonpharmacological therapies (complementary) in nursing services for hypertensive clients in the future.

\section{Methods}

The purposive sampling technique made sample selection. This research was conducted during the COVID-19 pandemic. According to inclusion and exclusion criteria, the sample selection was based on proximity to the enumerator, family, and closest neighbors. The samples in this study were pre-elderly and elderly who suffer from hypertension. The inclusion criteria were set for pre-elderly and elderly patients with mild to moderate primary hypertension. They were willing to be respondents, while the exclusion criteria were hypertension with complications/severe comorbidities and garlic allergy. The sample calculation using the sample size formula from Dahlan (2013), with an anticipated drop out of $10 \%$, obtained a total sample of 34 respondents [8].

Before the study, the enumerators were given training and equalized perceptions of filling out questionnaires, interviewing techniques, and measuring BP and deep breathing relaxation techniques. The instruments used are, among others, for the study of demographic data, namely, age, gender, height and weight, body mass index (BMI), long-suffering from HT, taking hypertension medication/ not. Measurements of pre-intervention BP, BP on day-3 intervention, and BP on post-intervention on day- 8 were measured. BP measurement using manual aneroid sphygmomanometer and stethoscope. Measurement of weight using analog scales and measurement of height using a meter tape. Measurement of Lifestyle, 17 questions consist of eight positive questions and nine negative questions, combining elements of physical activity, eating patterns, resting habits, and smoking habits. The form of the question is a closed question with "yes" and "no" answers [9].

Using the Perceived Stress Scale-10, the instrument on Stress Conditions has been standardized and has a high level of validity and reliability. This questionnaire created by Sheldon Cohen can measure the global perception of stress, which provides several essential functions regarding stress-causing conditions that can affect physical conditions or pathology, consisting of ten questions, with six negative questions and four positive questions. Each question is given a score from 0 to 4 . A score of 0 is chosen for never. A score of 1 was selected for rare. Score 2 is selected for some time. A score of 3 was selected for frequent. A score of 4 was selected for very often. This score is reversed to answer positive questions so that the score is $0=4$; the score is $1=3$, the score is $2=2$, and so on. Positive questions in this questionnaire are found in questions 4, 5, 7, and 8 . The stress level is known after adding up all the ten questions' scores in the stress questionnaire. A score of 13 shows the average value or is still said to be within normal limits. A stress score of 20 or more indicates severe stress.

Data collection activities were carried out by implementing the $3 \mathrm{M}$ health protocol, namely, using masks and face shields, maintaining distance, and washing hands frequently, then asking for a Statement of Approval After Explanation (PSP). Tension measurements were carried out two times, namely tension 1 (pre-intervention) with a measurement time of 3-5 min for the average. Then, the interview filled out the questionnaire, explaining the deep breathing relaxation technique and asking the respondent to demonstrate until it was perfect. Furthermore, it describes how and when to consume roasted garlic, which can be eaten directly or with other foods, when to consume roasted garlic in the morning and evening. Likewise, deep breathing relaxation. The roasted garlic was prepared by researchers in plastic bags for one-time consumption; researchers prepared roasted garlic for the first 3 days of the first intervention period, days four to seven were given freshly roasted garlic for the second period. Roasted garlic is not made and given all at once because it keeps the quality of the onions from getting stale and watery. Respondents were given a control card filled with the date and time for deep breathing relaxation and consumption of roasted garlic in the morning and evening. Likewise, enumerators were provided with a control card filled with the date of BP measurement preintervention, day 3 , and post-intervention.

Data analysis using SPSS version 25 software. The following steps of research are Univariate, bivariate analysis with dependent sample t-test (paired t-test) and statistical tests of correlation and simple linear regression. 


\section{Results}

The results of the univariate analysis are in Table 1, of which the 34 respondents, most of them are female 27 people $(79.4 \%)$ and only seven respondents $(20.6 \%)$ are male. Most of the respondents, 25 people $(73.5 \%)$, used hypertension medication, with each respondent's lifestyle 17 people $(50 \%)$ having a good lifestyle, and the proportion of stress levels most of the respondents experiencing moderate stress 27 (79.4\%) and stress. mild 7 people (20.6\%).

Table 1: Frequency distribution of respondents characteristics on categorical variables $(n=34)$

\begin{tabular}{lll}
\hline Characteristics & N & $\%$ \\
\hline Sex & 7 & \\
$\quad$ Male & 27 & 21 \\
$\quad$ Female & & 79 \\
Using anti-hypertensive drugs & 25 & 74 \\
$\quad$ Yes & 9 & 27 \\
$\quad$ Not & & \\
Lifestyle & 17 & 50 \\
$\quad$ Good & 17 & 50 \\
$\quad$ Not Good & 7 & 21 \\
Level stress & 27 & 79 \\
$\quad$ Mild & 27 \\
Moderate &
\end{tabular}

In Table 2, the youngest age is 45 years, the oldest 65 years; the average respondent is 54.47 years with a median of 53.50 years and a standard deviation of 6.48 years. The lowest body mass index was 15.60 , the highest was 55.60, and the average body mass index was 21.00 , with a median of 20.35 and a standard deviation of $6.59 \mathrm{BMI}$. For the duration of respondents suffering from hypertension, the lowest was 1 year, and the longest was 25 years with a mean of 7.47 years with a median of 4.5 years and a standard deviation of 7.29 years. BP increases both systolic and diastole directly proportional to age; systolic BP increases progressively until the age of $70-80$ years while diastolic BP increases until the age of 50-60 years and then tends to stay or decrease slightly. In the respondents of this study, hypertension may be associated with changes in the structure of the arteries so that there has been stiffness and a decrease in the flexibility of the first arteries related to age because the average age of the respondents is 54.47 years and includes other contributing factors such as BMI, duration of hypertension, lifestyle and stress levels.

Table 2: Frequency distribution of respondents characteristics on numerical variables $(n=34)$

\begin{tabular}{llllll}
\hline Variable & Min & Max & Mean & Median & SD \\
\hline Age & 45 & 65 & 54.47 & 53.5 & 6.48 \\
Boddy mass index & 15.6 & 55.6 & 21.01 & 20.35 & 6.59 \\
Hypertension duration & 1 & 25 & 7.47 & 4.5 & 7.29 \\
\hline
\end{tabular}

In Table 3, the frequency distribution of preintervention systolic BP is between $130 \mathrm{mmHg}$ and $191 \mathrm{mmHg}$; the mean is $148.85 \mathrm{mmHg}$. The median value (median) is $147.50 \mathrm{mmHg}$ with a standard deviation of $12.71 \mathrm{mmHg}$. After the intervention on the $3^{\text {rd }}$ day, the systolic BP range decreased between $115 \mathrm{mmHg}$ to $170 \mathrm{mmHg}$, the mean was $142.29 \mathrm{mmHg}$, and the median value (median) was $140 \mathrm{mmHg}$ with a standard deviation of $12.69 \mathrm{mmHg}$. However, on day seven or post-intervention systole, there was no decrease, with a range of $120 \mathrm{~mm} \mathrm{Hg}$ to $182 \mathrm{~mm} \mathrm{Hg}$, a mean of 141.98 $\mathrm{mm} \mathrm{Hg}$, and a median value of $140.50 \mathrm{~mm} \mathrm{Hg}$ with a standard deviation of $12.21 \mathrm{~mm} \mathrm{Hg}$. The frequency distribution of pre-intervention diastolic $\mathrm{BP}$ was between $80 \mathrm{mmHg}$ to $110 \mathrm{mmHg}$; the average was $92.29 \mathrm{mmHg}$, the median value was $90 \mathrm{mmHg}$ with a standard deviation of $7.87 \mathrm{mmHg}$. After the $3^{\text {rd }}$ day, it tends to decrease to $80 \mathrm{~mm} \mathrm{Hg}$ to $107 \mathrm{~mm} \mathrm{Hg}$; the mean is $88.47 \mathrm{~mm} \mathrm{Hg}$, the median value is $90 \mathrm{~mm} \mathrm{Hg}$ with a standard deviation of $7.99 \mathrm{~mm} \mathrm{Hg}$. On day 7 or post-intervention, diastole did not decrease or persist, between $80 \mathrm{mmHg}$ to $110 \mathrm{mmHg}$, mean $89.69 \mathrm{mmHg}$, median value (median) $90 \mathrm{mmHg}$ with a standard deviation of $6.98 \mathrm{mmHg}$.

Table 3: Distribution of systolic and diastolic BP in district West Bogor, Bogor city, $2020(n=34)$

\begin{tabular}{llllll}
\hline BP & Min & Max & Mean & Median & SD \\
\hline Pre-Intervention Systole & 131 & 191 & 149 & 147.5 & 12.7 \\
$3^{\text {rd }}$ day of intervention (systole) & 115 & 170 & 142 & 140 & 12.7 \\
Post-Intervention Systole & 120 & 182 & 142 & 140 & 12.2 \\
Pre Intervention Diastole & 80 & 110 & 92.3 & 90 & 7.87 \\
$3^{\text {rd }}$ day of intervention (diastole) & 80 & 107 & 88.5 & 90 & 7.99 \\
Post Intervention Diastole & 80 & 110 & 89.7 & 90 & 6.98 \\
\hline BP. Blood pressure
\end{tabular}

\section{T-dependent test}

In Table 4, pre-intervention systolic BP is $148.85 \mathrm{mmHg}$, with the $3^{\text {rd }}$-day intervention $142.29 \mathrm{mmHg}$, with a significant value of $0.006(95 \%$ $\mathrm{Cl}$; 3.45-9.67), meaning that there is a significant difference in pre-intervention systolic BP. With and systolic $\mathrm{BP}$ on the $3^{\text {rd }}$ day of the intervention, with an interval of $3.45-9.67 \mathrm{mmHg}$. Post-intervention systolic BP is $141.98 \mathrm{mmHg}$ with a significant value of $0.000(95 \% \mathrm{Cl} ; 3.49-10.24)$, meaning a significant difference in the mean value of pre-intervention and post-intervention systolic BP with an estimated interval of 3.49-10.24 mmHg.

Table 4: Respondent's average systolic and diastolic BP in west bogor district, $2020(n=34)$

\begin{tabular}{llllllll}
\hline BP & Mean & SD & SE & Selisih & SD & Sig & $95 \% \mathrm{Cl}$ \\
\hline Systole & & & & & & & \\
$\quad$ Pre intervention & 148.85 & 12.72 & 2.18 & & & & \\
$\quad 3^{\text {rd day of intervention }}$ & 142.29 & 12.69 & 2.17 & 6.56 & 8.91 & 0.006 & $3.45-9.67$ \\
$\quad$ Post intervention & 141.98 & 12.09 & 2.09 & 6.86 & 9.68 & 0.000 & $3.49-10.24$ \\
Diastole & & & & & & & \\
$\quad$ Pre intervention & 92.3 & 7.9 & 1.35 & & & & \\
$\quad 3^{\text {rd day of intervention }}$ & 88.5 & 8 & 1.37 & 3.82 & 7.51 & 0.006 & $1.2-6.44$ \\
$\quad$ Post intervention & 89.7 & 7 & 1.19 & 2.6 & 9.04 & 0.103 & $-55-5.75$ \\
\hline BP: Blood pressure & & & & & & &
\end{tabular}

It shows a significant difference in the mean pre-intervention diastolic BP and diastolic BP on the $3^{\text {rd }}$ day. Pre-intervention diastolic BP was $92.29 \mathrm{mmHg}$ with the $3^{\text {rd }}$-day intervention $88.47 \mathrm{mmHg}$, with a significance of $0.006(95 \% \mathrm{Cl}: 1.2-6.44)$. Postintervention diastolic BP was $89.69 \mathrm{mmHg}$ with a significant value of $0.103(95 \% \mathrm{Cl}$; $-55-5.75)$, meaning that there was no significant difference in the mean value of pre-intervention and post-intervention diastolic $\mathrm{BP}$, with an estimated pressure interval diastolic blood $-55-5.75 \mathrm{mmHg}$. 


\section{Linear regression and correlation test}

Table 5 shows the relationship between age and the average decrease in systolic BP shows a moderate relationship $(r=0.46)$. It has a positive pattern meaning that increasing age will increase the average systolic BP; the determinant coefficient value is 0.21 . It implies the regression line equation obtained can predict only a $21 \%$ decrease in mean systolic BP; other factors determine the rest. The results of the statistical test $p=0.006$, there was a significant relationship between age and an increase in the mean systolic BP. The line equation can be interpreted that for every 1-year increase in age from the average age, the systolic BP will decrease $-52.52 \mathrm{mmHg}$ plus $0.32 \mathrm{mmHg}$ multiplied by age. There is no significant relationship between age, BMI variable, and length of suffering from hypertension.

Table 5: Numerical variable correlation and regression with mean decrease in systolic blood pressure

\begin{tabular}{|c|c|c|c|c|}
\hline Variable & $\mathrm{r}$ & R2 & Line Equation & $\mathrm{p}$-value \\
\hline \multirow{5}{*}{ Age } & 0.33 & 0.109 & Average Systolic drop & 0.057 \\
\hline & & & Day $3=-17.67+0.446^{*} U$ & \\
\hline & 0.005 & 0 & $\begin{array}{l}\text { Average decrease in Diastolic } \\
\text { Day } 3=53.86+0.19^{*} U\end{array}$ & 0.977 \\
\hline & 0.464 & 0.215 & $\begin{array}{l}\text { Average decrease in post } \\
\text { systolic }=-52.51+0.32^{*} \mathrm{U}\end{array}$ & 0.006 \\
\hline & 0.273 & 0.75 & $\begin{array}{l}\text { Average post-diastolic } \\
\text { decline }=53.86+0.19^{*} U\end{array}$ & 0.118 \\
\hline \multirow[t]{4}{*}{$\begin{array}{l}\text { Boddy mass } \\
\text { index }\end{array}$} & 0.073 & 0.005 & $\begin{array}{l}\text { Average Systolic drop } \\
\text { Day } 3=4.492+0.098^{*} \mathrm{IMT}\end{array}$ & 0.683 \\
\hline & 0.088 & 0.008 & $\begin{array}{l}\text { Average decrease in Diastolic } \\
\text { Day } 3=1.713+0.100^{*} \mathrm{IMT}\end{array}$ & 0.62 \\
\hline & 0.269 & 0.072 & $\begin{array}{l}\text { Average decrease in post } \\
\text { systolic }=22.26+(-0.183)^{\star} \text { IMT }\end{array}$ & 0.124 \\
\hline & 0.007 & 0.000 & $\begin{array}{l}\text { Average post-diastolic } \\
\text { decline }=20.99+005^{*} \mathrm{IMT}\end{array}$ & 0.969 \\
\hline \multirow{4}{*}{$\begin{array}{l}\text { Long suffering } \\
\text { hypertension }\end{array}$} & 0.2 & 0.04 & Average Systolic drop & 0.258 \\
\hline & 0.111 & 0.012 & $\begin{array}{l}\text { Day } 3=8.439+(-0.241)^{*} \mathrm{LM} \\
\text { Average decrease in Diastolic } \\
\text { Day } 3=4.706+(-0.113)^{*} \mathrm{LM}\end{array}$ & 0.532 \\
\hline & 0.107 & 0.11 & $\begin{array}{l}\text { Average decrease in post } \\
\text { systolic }=7.233+0.82^{\star} \mathrm{LM}\end{array}$ & 0.546 \\
\hline & 0.99 & 0.01 & $\begin{array}{l}\text { Average post-diastolic } \\
\text { decline }=7.58+0.81^{*} \mathrm{LM}\end{array}$ & 0.578 \\
\hline
\end{tabular}

Table 6 shows no significant relationship between stress and the average decrease in systole on the $3^{\text {rd }}$ day. The average reduction in diastole on the $3^{\text {rd }}$ day of the intervention, the average decrease in post systole, the average decrease in post diastole ( $p>0.005)$, and the Lifestyle variable, there is no significant significance relationship.

Of the five variables, namely age, BMI, duration of hypertension, stress, and lifestyle test results correlation and simple linear regression on the decrease in systolic and diastole BP on the $3^{\text {rd }}$ day of intervention and post-intervention, only one significant variable, namely the age variable $(p=0.006)$.

\section{Discussion}

In general, there is a difference in the average decrease in BP before and on the $3^{\text {rd }}$ day of the intervention, pre, and post-intervention, because deep breathing relaxation and garlic consumption are complementary therapies beneficial in lowering $\mathrm{BP}$. These results are in line with research conducted by Anggraini (2019) that the effects of pre-breath relaxation most of the respondents had stage 2 systolic BP $(56.7 \%)$ and an average value of $161 \mathrm{mmHg}$, a minimum systolic BP of $130 \mathrm{mmHg}$, and a maximum of $210 \mathrm{~mm} \mathrm{Hg}$ [10]. The pre-relaxation diastolic BP was in the majority in stage 1 hypertension (36.7\%), and the average value was $92 \mathrm{mmHg}$, a minimum of $76 \mathrm{mmHg}$, and a maximum of $120 \mathrm{mmHg}$. Post-breath relaxation in normal systolic BP (56.7\%) and the average value of $120 \mathrm{mmHg}$, a minimum of $100 \mathrm{mmHg}$ and a maximum of $160 \mathrm{mmHg}$, with a p-value of $0.000(<0.005)$ and a diastolic BP after a normal breath relaxation intervention (76.7\%) and an average value $74.33 \mathrm{mmHg}$, a minimum mean of $64 \mathrm{mmHg}$ and a maximum of $90 \mathrm{mmHg}$ and the $\mathrm{p}$-value obtained is $0.000(<0.005)$.

Table 4 shows a significant difference in the mean value of pre-intervention and postintervention systolic BP with an estimated interval of $3.49-10.24 \mathrm{mmHg}$ with a significant value of 0.000 (95\% Cl; 3.49-10.24).

Another study conducted by Juwita and Efriza in 2018 showed a significant difference in the mean TDS before and after treatment of $7.51 \mathrm{mmHg}$ with a p-value of 0.000 and the mean diastolic BP before and after treatment $5.85 \mathrm{mmHg}$. Deep breathing relaxation therapy can reduce systolic BP by $18.46 \mathrm{mmHg}$ and diastolic BP by $6.54 \mathrm{mmHg}$ with a p-value of 0.001 [11]. Another similar study showed that the control group's systolic and diastolic BP did not experience significant changes (systolic $p=0.665$ and diastolic $p=0.825$ ). In contrast, the pressure in the experimental group had a significant value $(p$ systolic $=0.000)$ and $\mathrm{p}$ diastolic $=0.000$ ) [12]. Research conducted by Rahayuningrum and Herlina in 2019 showed that giving garlic (Allium Sativum) water can reduce BP in hypertensive patients with a systolic $p$-value of 0.004 and a diastolic p-value of 0.042 [13]. Izzati and Luthfiani conducted a similar study in 2017 . The results showed an effect of garlic boiled water on the BP of hypertensive patients with a p-value of 0.045 [14].

Table 6: Correlation and regression of lifestyle and stress with a mean reduction of systolic and diastolic blood pressure in sub-districts West Bogor Bogor City, $2020(n=34)$

\begin{tabular}{llll}
\hline Variable & $\mathrm{R}$ & $\mathrm{R} 2$ & Line Equation \\
\hline Stress & 0.017 & 0 & $\mathrm{p}$ value \\
& 0.155 & 0.024 & $3^{\text {rd }}$ Day Systolic Decrease Average $=7.246+(-0.40)^{*}$ Stress \\
& 0.168 & $3^{\text {rd }}$ Day Diastole Average average $=9.136+\left(-0.311^{*}\right.$ Stress & 0.924 \\
& 0.098 & Average decrease in post systolic $=14.299+(-0.435)^{*}$ Stress & 0.381 \\
Lifestyle & 0.099 & 0.01 & Post-diastolic decrease Average $=6.622+(-0.235)^{*}$ Stress \\
& 0.124 & 0.01 & $3^{\text {rd }}$ Day Systolic Decrease Average $=3.698+0.370^{*} \mathrm{GH}$ \\
& 0.214 & 0.015 & $3^{\text {rd }}$ Day Diastole Average decrease $=0.781+0.393^{*} \mathrm{GH}$ \\
& 0.115 & 0.013 & $3^{\text {rd }}$ Day Diastole Average decrease $=0.119+0.872^{*} \mathrm{GH}$ \\
& & Post-diastolic decrease average $=-0.793+0.439^{*} \mathrm{GH}$ \\
\hline
\end{tabular}


The literature study showed that deep breathing relaxation therapy and garlic consumption, which were studied alone, had a significant impact on reducing $\mathrm{BP}$ in patients with hypertension, and the results of this study in combination. Deep breathing relaxation is one of the complementary therapies that is often used in nursing interventions, both in pain, anxiety, and hypertension patients. Slow deep breathing relaxation lowers BP in several ways. The first is by increasing the sensitivity of baroreceptors and releasing endorphins neurotransmitters to stimulate autonomic nervous responses. Second, by inhibiting the sympathetic center (increasing body activity). Third, by stimulating parasympathetic activity (reducing activity or relaxing the body). If this condition occurs regularly, it will activate the cardiovascular control center, which will cause a decrease in heart rate, stroke volume, thereby reducing cardiac output; this process has the effect of lowering BP. The physiological function of deep breathing therapy can respond to increased baroreceptor activity and decreased sympathetic nerve activity. After that, there will be a decrease in contractility and a decrease in strength with each beat. It results in a reduction of stroke volume and a decrease in cardiac output. It can lower BP and thus reduce anxiety [15], [16]. Excellent and correct deep breathing relaxation techniques will have essential effects on the body, including decreased pulse, $\mathrm{BP}$, breathing, reduced oxygen consumption, reduced muscle tension, and decreased metabolic rate [17].

The results of the combination study between deep breathing relaxation and consumption of roasted garlic did not have a synergistic therapeutic effect compared to the other studies described above. The researcher's hypothesis was not proven, where the results obtained were not much different before and after the intervention in the combination.

Table 6 shows no significant relationship between stress and the average decrease in systole on the $3^{\text {rd }}$ day. The average reduction in diastole on the $3^{\text {rd }}$ day of the intervention, the average decrease in post systole, the average decrease in post diastole ( $p>0.005)$, and the Lifestyle variable, there is no significant significance relationship.

Of the five variables, namely age, BMI, duration of hypertension, stress, and lifestyle test results correlation and simple linear regression on the decrease in systolic and diastole BP on the $3^{\text {rd }}$ day of intervention and post-intervention, only one significant variable, namely the age variable $(p=0.006)$. The results of Elsanti's research (2009) in Nuraini's (2015) study, that age can increase the risk of hypertension. It means that age affects the outcome of the intervention, namely a decrease in BP. These changes cause a decrease in the compliance of the aorta and great vessels. The result is an increase in systolic BP. An increase in systolic BP will increase the workload of the heart and will eventually result in a thickening of the left ventricular wall as a compensation/adaptation effort [18], [19].

\section{Conclusion}

1. Characteristics of respondents, most women with an average age of 54.47 years, the average length of suffering from hypertension 7.47 years, an average body mass index of 21 , most of them taking routine hypertension drugs $67.7 \%$, the respondent's lifestyle is between good and not good comparable, with stress levels partially in the moderate range.

2. There is an effect of deep breathing intervention and consumption of roasted garlic before the intervention and the $3^{\text {rd }}$ day of the intervention on systolic blood pressure ( $p$-value 0.006 ) with a mean decrease of $6.56 \mathrm{mmHg}$

3. There is an effect of deep breathing intervention and consumption of roasted garlic before intervention and post-intervention on systolic blood pressure ( $p$-value 0.000) with a mean decrease of $6.86 \mathrm{mmHg}$

4. There is an effect of deep breathing intervention and consumption of roasted garlic before the intervention and the three interventions on diastolic blood pressure ( $p$-value 0.006 ) with a mean decrease of $3.82 \mathrm{mmHg}$

5. There is no effect of deep breathing intervention and consumption of roasted garlic before and post-intervention on diastolic blood pressure (p-value 0.103) with a mean decrease of $2.60 \mathrm{mmHg}$

6. A correlation between age and the mean decrease in systolic blood pressure ( $p$-value 0.006 ) shows a moderate relationship and a positive pattern.

\section{Suggestion}

1. Further research is needed, with the design and target of other population groups to compare research results.

2. The study results can be used as an alternative to complementary therapy that is quite effective in lowering blood pressure that the community can do. Respondents can continue treatment with anti-hypertensive drugs that are easy, inexpensive, and have minimal side effects.

\section{Author's Contributions}

Authors 1 and 2 were assisted by enumerators when collecting data. Authors 1 and 2 prepared the data analysis proposal, while the enumerators were only involved in data collection. 


\section{Acknowledgment}

\section{Declarations}

Researchers get a lot of help from various parties. On this occasion, the researcher would like to express his deepest gratitude to the Bogor Nursing Study Program Educational Institutions and the Bandung Health Polytechnic of the Indonesian Ministry of Health, who financed the research in the Tri Dharma of State framework Universities. Acknowledgments to the Enumerators of Poltekes Bandung 2020 alumni for their involvement and their families for being willing to be respondents in this research. Hopefully, the results of this research can provide benefits to the world of nursing and society in general.

\section{References}

1. World Health Organization. Global Overview of Hypertension The Silent Killer, an International Public Health Crisis. Geneva: World Health Organization; 2013. Available from: http://www. who.int/cardiovascular_diseases/publications/global_brief_ hypertensi/en [Last accessed online on 2020 Nov29].

2. Indonesian Ministry of Health. Basic Health Research; RISKESDAS. Jakarta: Research and Development Ministry of Health RI; 2013.

3. Indonesian Ministry of Health. Directorate of P2M: Healthy Lifestyle Recommended to Prevent and Control Hypertension. Jakarta, Indonesia: Indonesian Ministry of Health; 2019.

4. Tawang E. Effect of moderate-severe deep breathing relaxation on blood pressure reduction in hypertensive patients in Irina c
Blu Prof.DR. R.D. Kandou Manado. Nurs J. 2013;1(1):1-7.

5. Hartanti RD. Breathing relaxation therapy in lowering blood pressure in hypertensive patients. Sci J Health. 2016;9(1):1-6.

6. Kartikasari A. Effects of Garlic (Allium sativum Linn) on Lowering Blood Pressure. Undergraduate Thesis. Maranatha Christian University; 2013.

7. Mohanis. Giving garlic steeped water against blood pressure reduction. J Appl Sci Technol. 2015;9(1):124-135.

8. Dahlan SM. Sample Size and Sampling Method. Jakarta: Salemba Medika; 2013.

9. Romauli. Midwifery Care Basic Concepts of Pregnancy Care. Yogyakarta: Nuha Medika; 2014.

10. Anggraini $Y$. The effectiveness of deep breathing relaxation techniques on blood pressure in hypertensive patients in Jakarta. JKFT J. 2019;5(1):41-7.

11. Juwita L, Efriza E. Effect of deep breathing on blood pressure in hypertensive patients. REAL Nurs J. 2018;1(2):51-9.

12. Suwardianto $H$, Kurnia $E$. The effect of deep breathing relaxation therapy on blood pressure changes in hypertension patients at the city health center in the Southern Region of Kediri city. Res J STIKES Baptist Hospital Kediri. 2011;4(1):38-50.

13. Rahayuningrum DC, Herlina $A$. The influence of white onion feeding water (Allium sativum) on blood pressure in hypertension patients. Medit Sci Health J. 2019;2(2):18-26.

14. Wisnatul i, Fanny I. The effect of garlic boiled water on blood pressure in hypertensive patients in the Tigo Baleh Health Center Work Area, Bukit Tinggi City. Afiyah J Health Sci. 2017;4(2):48-54.

15. Muttaqin A. Nursing Care of Clients with Cardiovascular System Disorders. Jakarta: Salemba Medika; 2009.

16. Hayati NI, Rahayu SM, Asih SL. Effect of progressive muscle relaxation technique on blood pressure in elderly with hypertension. Health Work Media. 2020;3(1):91-8.

17. Potter PA, Perry AG. Nursing Fundamental Textbook: Concepts, Processes, and Practices. $4^{\text {th }}$ ed., Vol. 2. Jakarta: EGC; 2006.

18. Elsanti S. Guide to Healthy Living Free of Cholesterol, Stroke, Hypertension and Heart Attack. Yogyakarta: Araska; 2009.

19. Nuraini B. Risk factors of hypertension. J Major. 2015;4(5):6-17. 